\title{
SEM Images of Naphthalic Amide Derivatives Appearing by the Substituent Effect of Ending Group
}

\author{
Doan Minh Phung, ${ }^{\dagger}$ Woo-Chul Jeong, ${ }^{\ddagger}$ Chang-Shik Choi, ${ }^{\S}$ and Ki-Hwan Lee ${ }^{\dagger}$
}

\author{
${ }^{\dagger}$ Departmentof Chemistry, Kongju National University, Kongju 314-701, Korea, *E-mail: khlee@kongju.ac.kr \\ ${ }^{\ddagger}$ Korea Research Institute of Chemical Technology, Daejeon 305-600, Korea \\ $\S$ Department of Oriental Medicine Resources, Far East University, Eumseong, Chungbuk 369-851, Korea, \\ *E-mail: cschoi@kdu.ac.kr
}

\begin{abstract}
The naphthalic amide derivatives were synthesized by simple condensation and were crystallized by acetonitrile solution. The SEM images of products with methyl group and nitro group, respectively, showed rod shape while the SEM images of products with other groups $\left(\mathrm{N}\left(\mathrm{CH}_{3}\right)_{2}, \mathrm{OCH}_{3}, \mathrm{H}, \mathrm{F}\right.$, and $\left.\mathrm{Cl}\right)$, respectively, showed plate shape. We were known from these results that the substituent of ending group played an important role in the crystallization of single molecule and the morphology of naphthalic derivatives could be controlled by only change of ending group in single molecule.
\end{abstract}

Nowadays, the photofunctional fluorescent materials is being actively studied for two reasons: first, the understanding of the physical processes in such systems is of fundamental interest and second, the prospects of their practical application for developing sensory, biochemical, medical, photo-electronic, illuminating light sources, flat displays and among other possible uses seem to be very attractive. ${ }^{1,2}$ Even though photofunctional fluorescent compounds have already been utilized in various fields, ${ }^{3}$ increasing demand for those having superior and multi-functionality is attracting further research interest. ${ }^{4}$ The serious element in designing and fabricating these materials is the control of their emission wavelength. ${ }^{5}$ The utilization of these results can be make them potentially useful for optoelectronic applications, particularly fabricating efficient light-emitting devices and sensors. ${ }^{6-10}$ One of the most exciting developments in this study is designing a linear conjugated system displaying both fluorescence and the desired function. ${ }^{11}$ In parallel with absorption and fluorescence properties in solvents, in solid state organic luminescent materials particularly with tunable luminescence are also great interest in recent years, because of their applications in the field of optoelectronic devices, including organic electroluminescence (EL), lightemitting diodes (LEDs), and optical sensors. Organic molecules, for example, flexible $\pi$-conjugated molecules show a weak luminescence in dilute solution but become a strong luminescence in the solid state due to the rigid formation of emissive species that use the applications of

*To whom correspondence should be addressed. E-mail:khlee@kongju.ac.kr

Received January 6, 2012: accepted January 17, 2012 these molecules in high density optical systems. ${ }^{12}$ However, until now, there has been reported on the development of the functionalized fluorescentmaterials related with the naphthalic derivatives, but there has not been studied on the development of morphology related with the crystallization of the fluorescent naphthalic derivatives. Therefore, we prepared various crystals of naphthalic derivatives on the basis of the substituent effect of ending group and obtained the unique SEM images of those crystals.

Herein, we report the interesting SEM images of those crystals in the viewpoint of solid-state study and the development of morphology of single molecule for the first time. As shown in Fig. 1, various functional groups from the electron withdrawing group $\left(\mathrm{X}=\mathrm{F}, \mathrm{Cl}, \mathrm{NO}_{2}\right)$ to electron donating group $\left(\mathrm{X}=\mathrm{CH}_{3}, \mathrm{OCH}_{3}, \mathrm{~N}\left(\mathrm{CH}_{3}\right)_{2}\right)$ in the para position of ending aromatic ring were introduced in the resultant naphthalic amide derivatives.

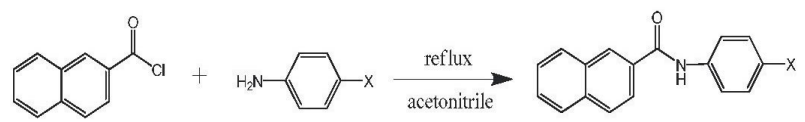

Fig. 1. Synthesis of $\mathrm{N}-\mathrm{p}-\mathrm{X}-$ pheny $1-2-$ naphthyl amide

The naphthalic amide derivatives were synthesized by refluxing 1 eq. of 2 -naphthoyl chloride and 1 eq. of aniline derivatives in $25 \mathrm{~mL}$ of acetonitrile. ${ }^{13}$ Upon refluxing, products were obtained as a precipitate.

After the reaction, the resultant solution was cooled to room temperature, filtered, recrystallized with ether, rinsed with solvents twice, and then dried in vacuum oven. All products were obtained as a moderate yield.
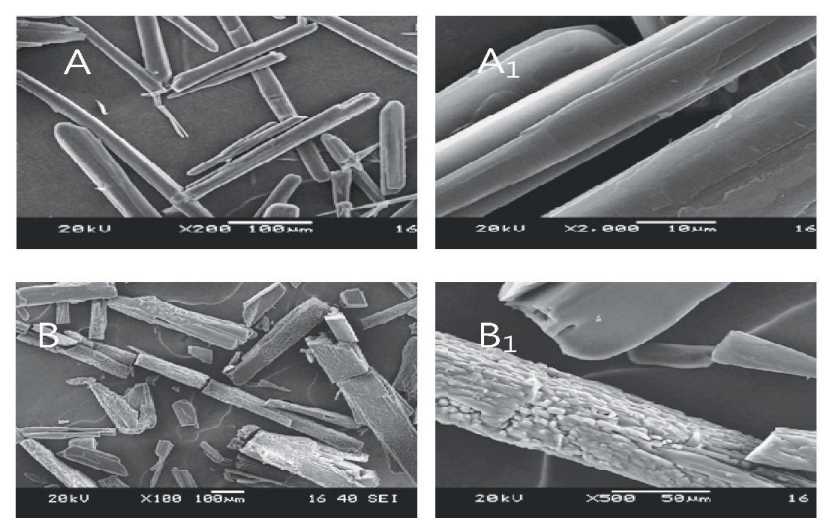

Fig. 2. SEM images of $\mathrm{N}-\mathrm{p}-$ methylphenyl-2-naphthyl amide (A, A1) and $\mathrm{N}-\mathrm{p}-$ nitrophenyl-2-naphthyl amide (B, B1) 
The SEM images of all products were observed as shown in Fig. 2 and Fig. 3. As shown in Fig. 2, the SEM images of products with methyl group and nitro group were shown as rod form even if product with methyl group showed clearer image than product with nitro group. However, as shown in Fig. 3, the SEM images of products with dimethyl group, methoxy group, nonsubstituent, fluorine group and chlorine group, respectively, were shown as a plate form. In particular, product with fluorine group showed very clear rectangular plate.
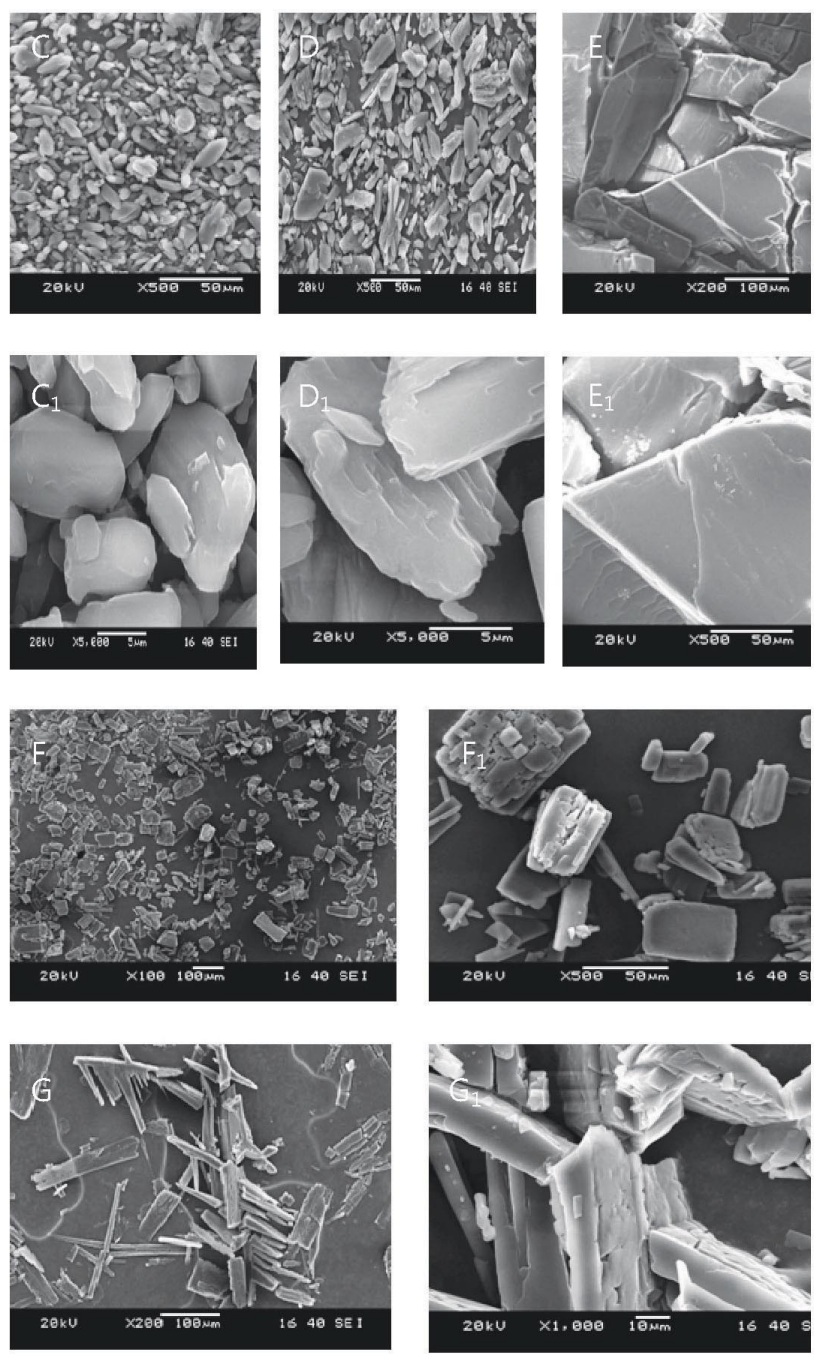

Fig. 3. SEM images of $\mathrm{N}-\mathrm{p}$-dimethylaminophenyl-2naphthyl amide $\left(\mathrm{C}, \mathrm{C}_{1}\right), \mathrm{N}-\mathrm{p}$-methoxyphenyl-2-naphthyl amide (D, D1), N-phenyl-2-naphthyl amide (E, E1), N-pfluorophenyl-2-naphthyl amide $\left(\mathrm{F}, \mathrm{F}_{1}\right)$, and $\mathrm{N}-\mathrm{p}-$ chlorophenyl-2-naphthyl amide (G, G1).

We were known from these results that the substituent of ending group played an important role in the crystallization of single molecule and the morphology of naphthalic derivatives could be controlled by only change of ending group in single molecule.
KEYWORDS: naphthalic amide derivatives, SEM image, substituent effect, crystallization

\section{ACKNOWLEDGEMENT}

This work was supported by the National Research Foundation of Korea (NRF) grant funded by the Korea government (MEST) (No. 20110015056) and Far East University.

\section{REFERENCES AND NOTES}

1. Chubich, D.A.; Fedorovich, R. D. Vitukhnovsky, A. G. J. Russ. Laser Res. 2008, 29( 4), 386-376.

2. Choi, C.-S. Jeon, K.S. Jeong W.C. Lee K.H. Bull. Korean Chem. Soc. 2010, 31(5), 1375.

3. (a) Fluorescent and Luminescent Probes for Biological Activity, ed. W. T. Mason, Academic Press, San Diego, 2nd edn., 1999 (b) Introduction to the Issue on Organic Electroluminescence (in IEEE J. Sel. Top. Quantum Electron., 1998, 4 ed. S. R. Forrest and P. E. Burrows, IEEE, New York, 1998.

4. Choi, C.-S. Mutai, T.; Arita, S.; Araki, K. J. Chem. Soc., Perkin Trans.2, 2000, 243.

5. Joshi, H. S.; Jamshidi R.;Y. Tor, Angew. Chem. Int. Ed., 1999, 38, 2722.

6. Jenekhe, S. A. Adv. Mater. 1995, 7, 309-311.

7. Hide, F.; Diar-Garcia, M. A. Schartz, B. J. Heeger, A. J. Acc. Chem. Res. 1997, 30, 430-436.

8. Peng, K. Y. Chen, S. A. Fann, W. S. J. Am. Chem. Soc., 2001, 123, 11388-11397.

9. Kraft, A.; Grimsdale, A. C. Holmes, A. B. Angew. Chem. Int. Ed., 1998, 37, 402-428.

10. Berggren, M.; Inganas, O.; Gustafsson, G.; Rasmusson, J.; Andersson, M. R. Hjertberg, T.; Wennerstrom, O. Letters to Nature, 1994, 372(1), 444-446.

11.Kraft, A.; Grimsdale, A. C.; Hormes, A. B. Angew. Chem. Int. Ed. 1998, 37, 402-428

12. Anthony, S. P. Varughese, S.; Draper, S. M. J. Phys.Org. chem., 2010, DOI 10.1002/poc,1757.

13. Every compounds were characterized by ${ }^{1} \mathrm{H}-\mathrm{NMR}$ and E.A.;one typical sample $(\mathrm{X}=\mathrm{CH} 3)$ : $\mathrm{mp} 189.2 \mathrm{oC},{ }^{1} \mathrm{H}$ NMR $\left(\mathrm{CDCl}_{3}\right) \delta$, ppm $2.34(\mathrm{~s}, 3 \mathrm{H}), 7.21(\mathrm{~d}, 2 \mathrm{H}), 7.56$ (q, 4H), 7.98 (m, 5H), 9.15 (s, 1H), EA calc. for $\mathrm{C}_{18} \mathrm{H}_{15} \mathrm{NO}$, C 82.732, H 5.786, N 5.360, found C 82.857, H 5.770, N 5.400. 